\title{
Coping Mechanism of Teenagers of Stress and Anxiety: A Case Study
}

\author{
Chrisafe Cyril N. Daga ${ }^{1}$ and Georgette M. Kempis ${ }^{2}$ \\ ${ }^{1}$ College of Education, Leyte Normal University, Tacloban City, 6500, Philippines \\ (chrisafecyril.daga@lnu.edu.ph) \\ ${ }^{2}$ College of Arts and Sciences, Leyte Normal University, Tacloban City, 6500, Philippines \\ (georgettem.kempis@lnu.edu.ph)
}

\begin{abstract}
Stress and anxiety start at the early development stage of adolescence. They increase the vulnerability of teenagers and the susceptibility to minor and sometimes severe illness. It is evident that teenagers, nowadays, go through stress at different levels. Indeed, teens have similarities with their experiences of stress across ethnicity, race, and economic background. With the increasing pressures of competition, particularly in a community with higher parental expectations and other factors, exploring coping mechanisms through the eyes of teenagers are needed to understand their experiences, identify the causes and explore supports that will help them cope, and initiate additional resources to support their health journey through teenage years and beyond.

This study aims to determine the prevalence of stress and anxiety and coping mechanisms among teenagers. This case study, which employed the Colaizzi method, was conducted among 15 teenagers of Leyte Normal University. Teenagers ranging from the age of 16-19 were engaged in conducting this study. Moreover, the overarching themes related to stress and anxiety identified by the participants included time, social relationships, and pressure in school. The themes related to coping identified by teenagers are a reflection of self and situations, positive relationships, finding an escape or distraction, making choices, and moving on. Furthermore, the participants drew two recommendations: establishing relationships, peer connections, time management, and coping skills.
\end{abstract}

Keywords: Case Study;Colaizzi Method;Qualitative Research;Stress and Anxiety

\section{Introduction}

The teenage year is a stage of life when many challenges take place-bodily changes, relationships with friends and parents, life goals, interests, dreams, and mental changes. There are times that these challenges influence each other, and sometimes they have nothing to do with being a teenager. In any case, the accumulation of varied stressors (and the anxiety they produce) faced during teenage years can be a lot for many teens to handle.

Nowadays, teenagers go through stress at different levels. They have common practical experiences of stress across race, ethnicity, and economic background, but there are stressful experiences during the teen years that vary due to the context of the community and school environment. Moreover, stress and anxiety happen when you see threat in the form of stress from any source such as requirement deadline, financial struggles, cruel classmates, etc. (Wright, 2017). Furthermore, what causes stress depends, at least in part, on your perception of it. According to (Essel \& Owusu, 2017), chemical stress (such as diet), emotional stress (such as loss of a loved one, nervousness, etc.), mental stress (negative outlooks, racing thoughts), and stress acquired physically can affect our cognition and our work force. However, identifying what causes our stress is the first step to managing the stress.

Coping is the method of dealing with and attempting to overcome problems and difficulties. Strategies in coping denote to the particular efforts, both in behavior and in psychology, that many try to master, endure, lessen, or minimize stressful occurrences. They aim to address, withstand or downscale the struggle of stress in situations or occurrences that individuals might sense vulnerable or threatened in the process of coping have been studied under various labels, including selfregulation, behavior, emotion, attention, and action regulation, ego-control, self-control, compliance, and violation. The reaction towards a stressor leads to the progress of some approach to cope that can depreciate or worsen the consequences of the condition. Naturally, teenagers' first step in managing and coping with anxiety and stress is to learn as much as they can about it, as a thorough understanding of their anxiety can itself reduce its frequency and intensity. It can be tempting to 
avoid any objects or situations that provoke or aggravate anxiety, but in the long term, such avoidance behavior is counterproductive.

Studies have explored stress and coping in teen years (Chandra \& Batada, 2004-2006); (Compas, Smith, Saltzman, Thompson, \& Wadsworth, 2001); (Lau, 2002); (Goodman, McEwen, Dolan, Schafer, \& Adler, 2005), but most have used quantitative methodologies, such as surveys, which do not allow for an in-depth description of the problem and richness of data specifically related to the context within which the problem exists. For this reason, it is a good approach in exploring the contextual nature of stress in teenagers. Teens have common experiences of stress across race, ethnicity, and economic background, but there are stressful experiences during the teen years that differ due to the context of the community and school environment. These differences warrant research. Studies are lacking in high-achieving communities where resources and attention may be deemed unnecessary.

\section{Literature Review}

Stress and Anxiety is a reality of our everyday life. At the point when individuals search for help, they are regularly managing conditions, circumstances, and stressors in their life that leave them feeling emotionally and physically troubled. Countless people, especially teenagers, feel that they have very little resources or assistance to deal with the high levels of stress they are experiencing.

According to (Wheeler, 2007), stress is a physics word that refers to the amount of force used on an object and it relates in real life as to how certain issues that carry force are applied to human life. Examples like financial difficulties, health challenge issues, conflicts with friends, all carry force or pressure on a person's body --- mind and spirit. Some of the burden sometimes come from the environment but often times come from an individual's head in the form of regret, worry, discouragement, anxiousness, and low confidence.

Stress is not only triggered by negative things that happen but even positive things also cause stress. People regard stress to be bad but that is not the case. There are two types of stressors, which are the positive stressors, which are known as eustress, and negative stressors, which are also known as, distress (Centre, 2010). Some positive situations cause a person to be stressed up. Some examples of these circumstances are, a promotion at work, starting a new job, getting married moreover, and stress is explained as "An uncertain reaction to external and internal factors" that means a negative or positive reaction to environmental stimuli. In this regard, it is how the totality of your body relates to changes and unfamiliar situations that present themselves in the course of time (Pargman, 2006).

Also, the sources of stress more specifically as a unique set of stressful encounters among students include difficult financial challenges, domestic responsibilities, responsibilities related to holding a job while in school, and a heavy academic load (Phinney \& Haas, 2003).

Students accumulate a handful of stressful experiences. Students' academic performances can be affected by many factors. The sources of stress are in every circumstance or event that threatens to disrupt people's daily functioning and causes them to make adjustments (Bernstein, D.A, Penner, L.A, Stewart, A.C \& Roy, E.J., 2008).

\section{Coping Mechanism}

The defense is the act of defending someone or something from attacks.

Adaptive having an ability to change to suit different conditions.

Avoidance means avoiding something.

Attack means to act violently against (someone or something): to try to hurt, injure, or destroy (someone or something).

Behavioral is the way a person or animal acts or behaves.

Cognitive pertains to and involves conscious mental endeavors which include thinking, understanding, learning, and remembering.

Self-harm is also known as self-injury, is defined as the intentional, direct injuring of body tissue, done without suicidal intentions.

Conversion is the act or process of changing from one form, state, etc., to another. 
Anxiety

In the book "The Meaning of Anxiety" (May 2015), anxiety is explained as to how a person reacts or responds to stress, accepts and interprets. In this view, stress is seen as a journey to anxiety, thus anxiety is an outcome of stress and it is how an individual handles stress. A good handler of stress is likely to experience any form of anxiety. Whereas those without effective management skills are prone to a high level of anxiety.

Anxiety has been linked to poor academic performance. High levels of academic anxiety can negatively affect working memory (Owens, M., Stevenson, J., Hadwin, J. A., \& Norgate, R., 2012). Anxiety is also related with high levels of apprehension that can contribute to academic performance.

In addition, Huberty (2009) wrote an article about test and performance anxiety. When the article was written, Huberty was a professor and the director of Indiana University's School of Psychology Program. The article is highly educational and includes lists causes, characteristics, and types of anxiety. Huberty also mentioned interventions for school workers and parents. Features of anxiety can affect students, cognition, behavior, and physiology. High level of stakes testing can be very tough for students experiencing anxiety. Students are also susceptible from experiencing depression if they are having anxiety. Both educators and guardians can help students learn to cope with anxiety.

\section{Research Problem}

Many teens suffer from anxiety and stress when facing difficult academic tasks. Anxiety and stress can harm the information processing system. People with anxiety as well as stress have difficulty storing and retrieving information (Nelson \& Harwood, 2011). There is a number of students who are very difficult to formally or informally assess because of anxiety.

Considering the statement above, the research addressed the following questions:

1. What are the things that stress you?

2. What do you do for to overcome these stressors?

\section{Theoretical Framework}

The Social Cognitive Theory served as the theoretical framework that guides the study. The basic concept of this model is referred to as reciprocal determinism, an idea that emphasizes that behavior develops from constant interaction of people and their environment and that the subsequent behaviors influence these people and their environments (Hodges \& Videto, 2005). Anxiety is not directly caused by stressors. Rather, it is an individual's reaction to the perception of stressors. Stressors are physical, emotional, or social stimuli that an individual faces in daily life and may produce a feeling of tension and strain (Mackenzie, 2008).

The basic concepts of teenager stress and anxiety include causes, responses, and coping strategies; all of which affect how a teenager handles stress. In relation to our study, it seeks to understand and attach meaning to teenagers' behavior. This study address how social observer uses the information to arrive at conclusions for the causes of stress and anxiety. This study is concerned with how and why teenagers explain events as they do.

Another theory that will guide the study and will support the social cognitive theory is the 8 Stages Theory of Identity and Psychosocial Development of Erik Erikson (David, 2014) since psychosocial is having both psychological and social aspects. Erikson's psychosocial theory of development contemplates the effect of external factors, guardians, and environment on personality growth from childhood to adulthood. This study focuses on a specific stage from Erick's theory, which is the fifth stage or the Adolescent stage. Every person has his or her own unique individuality. This identity is composed of the different personality traits that can be considered positive or negative and these personality traits can also be innate or acquired, and they vary from one person to another based on the degree of influence that the social environment has on the individual.

The accumulated information and explanations of the causes of stress and anxiety through social cognitive theory from the teen perceivers will be supported by the fifth stage of psychosocial theory. 


\section{Methodology}

This study aimed to explore teenagers' stressors and coping skills and to identify what could be put into place to further assist them in coping. This section discusses the research design used in the study being pursued, the description of the research environment and research respondents as well as a comprehensive discussion of the research instrumentation. It also outlines the steps of the data gathering procedures and analysis, which followed the major phases of the Colaizzi method.

\subsection{Research Design}

This research adheres to Yin's qualitative descriptive single-case study (2003). The researchers would like to describe the experiences of the students in their previous years, in terms of academic pressure and other factors that contribute to anxiety and stress.

\subsection{Data Collection}

The researcher will be collecting the data needed in the study by interviewing 15 randomly selected participants.

\subsection{Data Analysis}

The participant's responses were coded and analyzed through the aid of Braun and Clarke's thematic analysis (2006). The thematic analysis takes in cutting across data and searching for patterns and themes (Bondas, 2013). Thematic analysis is performed through the process of coding in six phases: (1) familiarization with data, (2) generating initial codes, (3) searching for themes among codes, (4) reviewing themes, (5) defining and naming themes, and (6) producing the final report- to create established, meaningful patterns In analyzing qualitative data, the thematic analysis offers an accessible and theoretically flexible approach (Braun \& Clarke, 2006).

\subsection{Ethical Considerations}

The participants were given the freedom of expressing their thoughts and views in a way they are comfortable with. After the data gathering, the researchers informed the participants about the following activities to be conducted. Lastly, the Researchers did not share information between participants and have procedures in place to protect the data and names of participants. The confidentiality and anonymity of the participants were taken into consideration.

\subsection{Triangulation}

The researchers conducted focus group discussions, wherein the students ask about their opinions, perceptions, and experiences during their previous years in basic education related to the topic. It was done in a classroom with a short interview with the students.

\section{Results and Discussion}

After analyzing the data gathered through the Colaizzi method, the following themes surfaced:

Theme 1 talks about the causes of anxiety and stress shared by the participants which are their academics, their social life, and personal life. Research, consecutive deadlines, and the additional two years in school are few academic stressors of the participants. Social media and cyberbullying are part of the social stressors of the participants while the expectations of the family and the judgment of other people are the personal stressors of the participants.

\subsection{Table1. Theme 1: Causes of Anxiety and Stress among Teenagers}

\begin{tabular}{lll}
\hline Academic & Social & Personal \\
\hline Research & Social media & Expectations of family \\
Additional two years in school & Cyberbullying & Judgement from other people \\
Too much assignments & & \\
\hline
\end{tabular}


Here are some of the transcribed responses of the participants.

"Consecutive deadlines Naka-pressure, projects (Participant 1)."I feel pressured because of consecutive deadlines and projects.

"A lot of requirements, projects, expectations coming from the teacher (Participant 2)."

Another theme also emerged upon the interpretation of the gathered data. These two talks about the coping mechanism of the participants when it comes to stress and anxiety. This theme has two categories which are the intrinsic and extrinsic coping mechanisms. For the intrinsic coping mechanism, the participants mentioned that they tend to motivate themselves to cope with stress, they also try to accept the challenges brought by stress, they set priorities and they manage their time. For the extrinsic coping mechanisms, they get strength from their family and seek the advice of their friends. Below is a graphical representation of the second theme.

\subsection{Table 2. Theme 2: Theme 2. Coping Mechanism of Teenagers of Stress and Anxiety}

\begin{tabular}{ll}
\hline Intrinsic & Extrinsic \\
\hline Self-motivation & Guidance of the family \\
Acceptance of the situation & Advice of friends \\
Self-confidence & \\
Time-management & \\
$\quad$ Setting Priority & \\
Self-disipline & \\
\hline
\end{tabular}

"Time-management, mag aadjust nala (Participant 3)." Time management, I am adjusting.

"Mayda time-management, self-discipline ngan know your priorities (Participant4)."I must be able to manage my time, have self-discipline and I should know my priorities.

\section{Summary}

After analyzing the data gathered, it was found out that there were several stressors of the participants that result in anxiety. Stressors such as research, assignments, and projects fall under academic stressors. Cyberbullying on social media falls under social stressors while the judgment of others and expectations of the family fall under personal stressors.

The participants have intrinsic and extrinsic coping mechanisms to avoid stress and anxiety. The intrinsic coping mechanism includes self-motivation, self-confidence, self-discipline, self-acceptance, priority setting, and time managing while the extrinsic coping mechanisms include the support of the family and the advice of peers.

\section{Conclusion}

One of the major stressors of the participants in the school requirements. Long exposure to social media can also be a source of stress among the participants. There may be a different source of stressors but the majority of the participants resort to self-determination in coping with stress and anxiety.

\section{Recommendation}

The following recommendations were drawn upon the interpretation of the data gathered:

1. Since the majority source of stress among teenagers is their academics, educators must devise a strategy that will lessen the pressure brought by this to teenagers.

2. To future researchers, reasons as to why these stressors are stressing teenagers may be a good problem to uncover.

\section{References}

Bernstein, D.A, Penner, L.A, Stewart, A.C \& Roy, E.J. (2008). Psychology. 8th edition. New York: Houghton Mifflin Company.

Centre, K. C. (2010). Stress and Stress Management. London: Press Books. 
Chandra, A., \& Batada, A. (2004-2006). Exploring Stress and Coping Among Urban African-American Adolescents; The Shifting the Lens Study. Preventing Chronic Disease Journal.

Compas, B. E., Smith, C. J., Saltzman, H., Thompson, A. H., \& Wadsworth, M. E. (2001). Coping with stress during childhood and adolescens: Problems, progress and potential in theory and research. Psychological Bulletin, 87-127.

David, L. (2014, July 23). Erikson's Theory of Identity and Psychological Development. Learning Theories, pp. 31-47.

Essel, G., \& Owusu, P. (2017). Causes of Students' stress; It's effects on their Academic Success and Stress Management of Students. International Business Journal, 21-29.

Goodman, E., McEwen, B. S., Dolan, L. M., Schafer, K. T., \& Adler, L. E. (2005). Social Disadvantage and Adolescent Stress. Journal of Adolescent Health, 484-492.

Hodges, B., \& Videto, D. (2005). Assessment and Planning Health Programs. Jones and Barlett Journal.

Huberty, T. J. (2009). Test and performance anxiety. Principal Leadership Journal, 12-16.

Lau, B. K. (2002). Does the stress of childhood and adolescence matter?; A Psychological Perspective. The Journal of the Royal Society for the Promotion of Health, 238-244.

Mackenzie, N. (2008). Social Cognitive: The Australian Educational Researcher. Autralian Journal of Mnagement, 89-104.

May, R. (2015). The Meaning of Anxiety. New York: Norton \& company Ltd.memory. School Psychology International.

Owens, M., Stevenson, J., Hadwin, J. A., \& Norgate, R. (2012). Anxiety and Depression in Teenagers. Health Journal.

Pargman, D. (2006). Managing performance stress models and methods. Britain: Routledge Taylor \& Francis group.

Phinney, J. S., \& Haas, K. (2003). The process of coping among ethnic minority of first generation:A narrative approach. The Journal of Social Psychology, 707-726.

Wheeler, C. M. (2007). Ten simple solutions to stress; How to maintain tension. Start enjoying our Life. USA: New Harbinger Publication Inc.

Wright, V. (2017). Stress Management: Rejuvenate the Mind, Body and Soul. Life Lived Forward Journal. 